\title{
Pharmacology and clinical potential of oblimersen sodium in the treatment of chronic lymphocytic leukemia
}

This article was published in the following Dove Press journal:

Blood and Lymphatic Cancer:Targets and Therapy

18 August 2012

Number of times this article has been viewed

\author{
Gautam Borthakur \\ Susan O'Brien \\ Department of Leukemia, \\ MD Anderson Cancer Center, \\ Houston, TX, USA
}

Correspondence: Susan O'Brien Department of Leukemia, MD Anderson Cancer Center, FC4.3020, 1515

Holcombe Blvd, Houston, TX 77030, USA

Tel +I 7I3 7927543

Fax +I 7135637746

Email sobrien@mdanderson.org

\begin{abstract}
Targeted inhibition of the Bcl-2 family of antiapoptotic proteins is expected to improve outcomes in chronic lymphocytic leukemia. Antisense oligonucleotides and small molecule inhibitors ( $\mathrm{BH} 3$ mimetics) are two approaches that have been used to target $\mathrm{Bcl}-2$ proteins. In this review, we summarize the experience with oblimersen sodium, an 18-base oligonucleotide targeting the first six codons of Bcl-2 mRNA, with particular focus on chronic lymphocytic leukemia. Despite evidence of improved outcomes in randomized trials of combination with chemoimmunotherapy, further development of this antisense approach has been slow, likely because of the clinical development of small molecule inhibitors.
\end{abstract}

Keywords: oblimersen, Bcl-2, antisense, chronic lymphocytic leukemia

\section{Introduction}

The mitochondrial pathway of apoptosis is the predominant mode of cancer cell death following treatment of malignancies with chemotherapy or most "targeted agents". Proteins of the Bcl-2 family are at the crossroads of apoptosis because they are involved in the integrity of the mitochondrial membrane. ${ }^{1-3}$ Disruption of mitochondrial membrane integrity is essential for initiating events leading to induction of apoptosis. ${ }^{4,5} \mathrm{Bcl}-2$ family members can be divided into two groups, ie, proapoptotic and antiapoptotic. Antiapoptotic members of the Bcl-2 family maintain the integrity of the mitochondrial membrane and thus prevent induction of apoptosis via the mitochondrial pathway, while coordinated activities of proapoptotic members lead to pore formation in the mitochondrial membrane (Figure 1).

The structure of Bcl-2 family proteins is characterized by the presence of Bcl-2 homology $(\mathrm{BH})$ domains. The antiapoptotic members, which include Bcl-2, Bcl-XL, Bcl-w, and Mcl-1, have four BH domains (BH1-4). The proapoptotic members can be divided into BH3 only (includes Bad, Blk, Bid, Bim, Bmf, Noxa, and PUMA) and BH1-3 (includes Bax and Bak). Of the BH3-only proteins, activated $\mathrm{Bid}^{6}$ and $\mathrm{Bim}^{7}$ activate Bax and Bak. Oligomerization of activated Bax and Bak forms pores in the mitochondrial membrane leading to release of cytochrome $c .{ }^{8-11}$ Bax also opens up voltage-dependent anion channels in the mitochondrial membrane facilitating cytochrome c release. Cytochrome $\mathrm{c}$ binds to Apaf-1, and the Apaf-1/cytochrome c complex binds to procaspase- 9 to bring about its autoactivation to caspase $9 .{ }^{12,13}$ Caspase- 9 in turn activates downstream caspase-3, caspase-6, and caspase-7.

Antiapoptotic Bcl-2 proteins prevent Bax/Bak oligomerization and pore formation in the mitochondrial membrane. There are multiple proposed models that seek to explain 


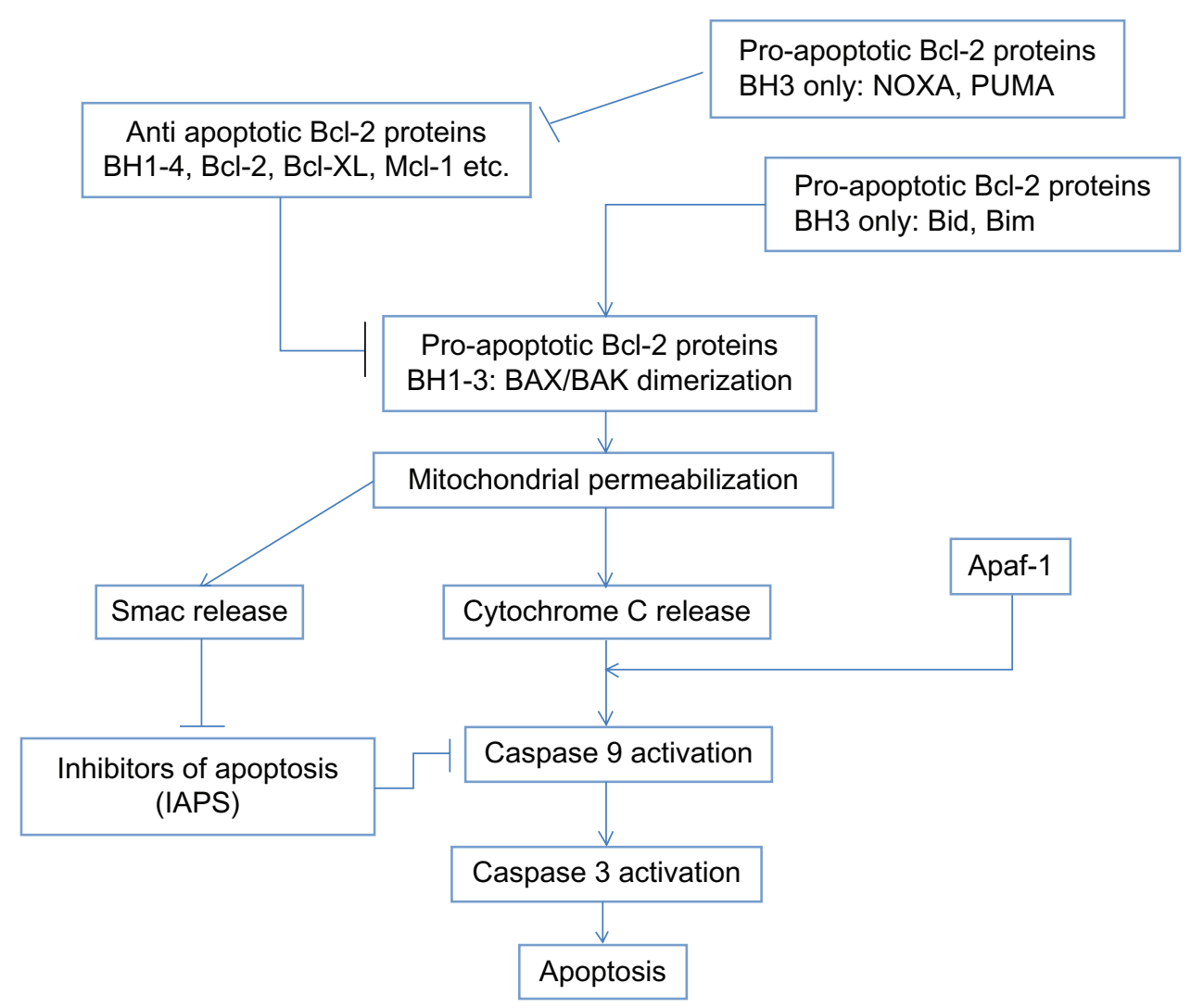

Figure I Schematic diagram of mitochondrial pathway of apoptosis.

the interaction between proapoptotic and antiapoptotic members of the Bcl-2 family. Without delving into the details, the proapoptotic $\mathrm{BH} 3$-only members sequester antiapoptotic Bcl-2 family proteins away from Bax and Bak and/or sequester antiapoptotic Bcl-2 proteins from activated Bid and Bim so that they in turn can activate Bax and Bak at the mitochondrial outer membrane, leading to their oligomerization and cytochrome $\mathrm{c}$ release. ${ }^{7,14,15}$

Beyond the antiapoptotic Bcl-2 family of proteins, inhibitors of apoptosis are a group of proteins that mitigate the activation of caspase- $9,{ }^{16}$ and thereby inhibit apoptosis. Smac is a mitochondrial protein that is released when cells undergo apoptosis and it promotes apoptosis by opposing the inhibitory influence of inhibitors of apoptosis. ${ }^{17}$

\section{Clinical relevance of $\mathrm{Bcl}-2$ proteins in hematolymphoid malignancies}

The role of the Bcl-2 family of proteins in hematological malignancies was unraveled by cloning of genes involved in the translocation (14;18), a hallmark of follicular lymphoma, that juxtaposes Bcl-2 to the immunoglobulin heavy chain gene resulting in constitutive expression of Bcl-2. ${ }^{18-20}$ Transgenic mice expressing the Bcl-2 immunoglobulin heavy chain fusion transgene showed lymphoid hyperplasia and follicular expansion, with increased survival of mature B cells. ${ }^{21}$

Apart from playing a pathophysiological role, Bcl-2 expression can also be linked with clinical outcome in lymphoid malignancies. Overexpression of Bcl-2 is associated with poorer outcome in patients with diffuse large B cell lymphoma ${ }^{22,23}$ and addition of rituximab to the standard regimen of cyclophosphamide, vincristine, doxorubicin, and prednisone appears to overcome the adverse prognostic impact of Bcl-2 overexpression. ${ }^{24}$

Mcl-1 expression in follicular lymphoma and mantle cell lymphoma is associated with higher-grade disease and this member of the Bcl-2 family of proteins is frequently expressed in myeloma cells. ${ }^{25,26} \mathrm{Mcl}-1$ is also overexpressed in anaplastic large cell lymphoma, suggesting that this may be the predominant antiapoptotic pathway in this lymphoma. ${ }^{27}$ In contrast, $\mathrm{Bcl}-2$ and $\mathrm{Bcl}-\mathrm{XL}$ are more frequently expressed in anaplastic lymphoma kinase-negative anaplastic large cell lymphoma. ${ }^{27}$

A defect in the apoptotic pathway is a hallmark of chronic lymphocytic leukemia (CLL), and differences in chemosensitivity may be attributable to Bcl-2 expression in CLL cells. ${ }^{28-30}$ Whereas Bcl-2 gene rearrangements are absent in 
CLL, Bcl-2 protein is overexpressed in CLL cells, ${ }^{31}$ indicating that disturbances in the balance between proapoptotic and antiapoptotic proteins may determine the susceptibility of cells to apoptotic signals. Overexpression of antiapoptotic $\mathrm{Bcl}-2$ leads to alteration in the $\mathrm{Bcl}-2 / \mathrm{BAX}$ ratio and tips the balance towards apoptosis resistance in CLL cells. ${ }^{28,29}$

\section{Development of $\mathrm{Bcl}-2$ inhibitors for clinical use}

Two strategies have been exploited for developing inhibitors of antiapoptotic members of the Bcl-2 family of proteins for clinical use. The first strategy uses antisense oligonucleotides targeting individual members of the Bcl-2 family of proteins. Single-stranded antisense oligonucleotides (12-25 nucleotides) are synthesized to be complementary to sequences in the mRNA of a particular protein, and by virtue of Watson and Crick base pair hybridization with this mRNA, they bring about degradation of mRNAs encoding for the target protein and cause downregulation of this protein. This concept has been tested in the context of Bcl-2. ${ }^{32-34}$ Oblimersen sodium is an 18-base phosphorothioate oligonucleotide complementary (antisense) to the first six codons of Bcl-2 mRNA, which leads to a selective decrease in concentrations of Bcl-2 mRNA and protein levels. ${ }^{35-37}$ The phosphorothioate backbone in oblimersen is resistant to nuclease and is expected to have good stability. By targeting the first six codons of Bcl-2 mRNA, oblimersen sodium, in addition to degradation of $\mathrm{Bcl}-2$, can potentially produce translational arrest.

The second strategy is to develop small molecules that can disrupt the inhibitory interaction of antiapoptotic Bcl-2 family proteins with proapoptotic members and can potentially target more than one antiapoptotic Bcl-2 family protein. Gossypol, AT101, obatoclax, ABT 263 (navitoclax), and ABT-199 are examples of the small molecule approach. Broadly, these agents are called $\mathrm{BH} 3$ mimetics because their interactions with antiapoptotic $\mathrm{Bcl}-2$ proteins mimic the binding of $\mathrm{BH} 3$ domain of proapoptotic members of Bcl-2 family to a hydrophobic pocket on antiapoptotic Bcl-2 proteins. ABT-263 and ABT-199 are drugs based on ABT-737, a small molecule Bcl-2 inhibitor specifically designed to target protein-protein interaction of proapoptotic and antiapoptotic members of Bcl-2 family. ${ }^{38}$ ABT-737 was designed by nuclear magnetic resonance-based screening of a chemical library for compounds that would disrupt binding of a Bak-derived peptide to a hydrophobic pocket of Bcl-X(L) and parallel synthesis, and inhibits $\mathrm{Bcl}-2, \mathrm{Bcl}-\mathrm{X}(\mathrm{L})$, and Bcl-w, as does ABT-263. On the other hand ABT-199 does not inhibit $\mathrm{Bcl}-\mathrm{X}(\mathrm{L})$.

\section{Preclinical studies with oblimersen sodium}

Lymphoma models in severe combined immunodeficiency mice using Bcl-2 overexpressing cell lines showed suppression of tumor growth by oblimersen either alone or in combination with cyclophosphamide. ${ }^{35,36}$ Because antisense oligonucleotides can potentially induce a tumor response by stimulating innate immunity, similar results were demonstrated in mice deficient in natural killer cells, indicating that the host immune system was not critical in elimination of lymphoma. The preclinical activity of Bcl-2 antisense is not necessarily restricted to tumors with genetic events leading to $\mathrm{Bcl}-2$ overexpression, because reduction in $\mathrm{Bcl}-2$ protein is expected to sensitize most tumors to chemotherapyinduced apoptosis. Bcl-2 antisense in combination with the CD20-targeted antibody, rituximab, also showed activity in preclinical models of indolent B cell malignancies and prolonged survival in tumor-bearing mice. ${ }^{39}$ These data formed the basis of combining oblimersen sodium with chemoimmunotherapy in B cell malignancies.

\section{Clinical experience with oblimersen sodium}

\section{Pharmacokinetic studies}

Based on the hypothesis that use of oblimersen sodium concomitantly with chemotherapy will sensitize cancers to chemotherapy by downregulation of Bcl-2, a number of Phase II and/or II studies of oblimersen sodium in combination with chemotherapies have been undertaken. Most studies have followed a design with oblimersen sodium administered alone followed by concomitant or tandem administration of chemotherapy.

In a Phase 1 trial including patients with hormone-refractory prostate cancer, oblimersen was administered on days 1-6 as a continuous infusion, with docetaxel administered on day $6 .^{40}$ Pharmacokinetic studies were carried out for both oblimersen and docetaxel, and peripheral blood mononuclear cells were collected before treatment and after treatment for measurement of Bcl-2 protein. Mean steady-state oblimersen concentrations were $3.44 \pm 1.31$ and $5.32 \pm 2.34$ microgram/ $\mathrm{ml}$ at the $5 \mathrm{mg} / \mathrm{kg} /$ day and $7 \mathrm{mg} / \mathrm{kg} /$ day dose levels, respectively. Doses beyond $7 \mathrm{mg} / \mathrm{kg}$ of oblimersen and $75 \mathrm{mg} / \mathrm{m}^{2}$ of docetaxel were associated with unacceptable neutropenia, so this dose was the recommended Phase II dose regimen.

A similar Phase I study of the combination of oblimersen and irinotecan in patients with metastatic colorectal cancer explored doses of 3-7 mg/kg/day by continuous infusion 
for oblimersen and $280-350 \mathrm{mg} / \mathrm{m}^{2}$ for irinotecan. ${ }^{41}$ Dose escalation beyond oblimersen sodium $5 \mathrm{mg} / \mathrm{kg} / \mathrm{day}$ and irinotecan $350 \mathrm{mg} / \mathrm{m}^{2}$ was not possible due to febrile neutropenia and diarrhea. Steady-state plasma concentrations of oblimersen sodium were reached within 48 hours of starting the infusion and dropped to undetectable levels 24 hours after discontinuation of the infusion. A continuous 5-day infusion schedule of oblimersen sodium (dose range 5-7 mg/kg/day) along with gemcitabine administered on day 5 (dose range $1000-1500 \mathrm{mg} / \mathrm{m}^{2}$ ) was studied in relapsed/refractory solid tumors, and steady-state plasma levels and the area under the curve of oblimersen were found to be dose-proportional. ${ }^{42}$ No formal dose-limiting toxicity was established.

More relevant to leukemias, a combination of oblimersen sodium by continuous infusion on days $1-10$ ( 4 or $7 \mathrm{mg} / \mathrm{kg} /$ day) with fludarabine, cytarabine, and granulocyte-colony stimulating factor on days 5-10 was administered to patients with relapsed/refractory acute myeloid leukemia. ${ }^{43}$ Fever, nausea, and fluid retention were encountered but were not considered to be dose-limiting. A similar study was done in older patients ( $\geq 60$ years of age) with newly diagnosed acute myeloid leukemia, and the treatment strategy included oblimersen sodium $7 \mathrm{mg} / \mathrm{kg} /$ day administered as a continuous intravenous infusion on days -10 , cytarabine $100 \mathrm{mg} / \mathrm{m}^{2} /$ day on days 4-10, and daunorubicin intravenously at two dose levels (dose level 1, $45 \mathrm{mg} / \mathrm{m}^{2} /$ day; dose level 2, $60 \mathrm{mg} / \mathrm{m}^{2}$ over 0.5 hours) on days $4-6 .{ }^{44}$ Patients in remission received high-dose cytarabine consolidation with oblimersen sodium. The pharmacokinetic profile of oblimersen sodium in both these studies was similar to that of the other studies mentioned earlier, with steady-state concentration achieved after 24 hours of infusion.

\section{Pharmacodynamic studies}

Pharmacodynamic studies with oblimersen sodium mostly consisted of quantifying the Bcl-2 protein level in peripheral blood mononuclear cells or tumor tissue by Western blot or enzyme-linked immunosorbent assay, or studying downregulation of Bcl-2 mRNA by reverse transcription polymerase chain reaction. ${ }^{40,41,43-45}$ Downregulation of the target, ie, Bcl-2, could be consistently demonstrated in these studies. In addition, Marcucci et al have shown intracellular uptake of oblimersen using an enzyme-linked immunosorbent assay. ${ }^{43,44}$

In the studies by Marcucci et al, ${ }^{43,44}$ paired measurement of Bcl-2 mRNA and protein levels was carried out in bone marrow mononuclear cells collected at baseline and before initiation of chemotherapy. Thus, potential confounding of the analysis by changes induced on chemotherapy was avoided. Reductions in Bcl-2 mRNA and protein levels following infusion of oblimersen could be demonstrated consistently and correlated with responses in one of the studies. ${ }^{44}$ Similar reduction in Bcl-2 protein levels in peripheral blood mononuclear cells and tumor tissue was demonstrated in studies in patients with hormone-refractory prostate cancers..$^{40,45}$

\section{Chronic lymphocytic leukemia}

A Phase I/II study in CLL included patients who received prior therapy with fludarabine. Oblimersen doses in the range of 3-7 mg/kg/day given by continuous infusion were explored in the Phase I part of the study, which accrued a total of 40 patients (16 in Phase I and 24 in Phase II). ${ }^{46}$ Oblimersen sodium was administered at doses ranging from 3 to $7 \mathrm{mg} / \mathrm{kg} /$ day as a 5 -day continuous intravenous infusion in cycle 1, and as a 7-day continuous intravenous infusion in subsequent cycles every 3 weeks in stable or responding patients. Hypotension and fever (attributed to a cytokine release syndrome) were the dose-limiting toxicities, and the maximum tolerated dose for Phase II dosing was established at $3 \mathrm{mg} / \mathrm{kg} /$ day. Tumor responses were seen in the form of reduction in hepatosplenomegaly, lymph node size, and reduction in lymphocyte counts.

A randomized Phase III trial was conducted in relapsed/ refractory CLL patients, with stratification based on prior response to fludarabine (responsive versus refractory), duration of response ( $>6$ months versus $\leq 6$ months), and number of prior regimens. ${ }^{47}$ Patients were randomly assigned to 28 -day cycles of fludarabine $25 \mathrm{mg} / \mathrm{m}^{2} /$ day plus cyclophosphamide $250 \mathrm{mg} / \mathrm{m}^{2} /$ day administered intravenously for 3 days with or without oblimersen $3 \mathrm{mg} / \mathrm{kg} /$ day as a 7-day continuous intravenous infusion (beginning 4 days before chemotherapy) for up to six cycles. The primary endpoint was response, ie, the proportion of patients achieving a complete response or nodular partial response. Overall survival was a secondary endpoint. Of 241 patients randomly assigned, complete response/nodular partial response was achieved in $20(17 \%)$ of 120 patients in the oblimersen group and eight (7\%) of 121 patients in the chemotherapy-only group $(P=0.025)$. Nausea and thrombocytopenia were more common in the oblimersen group.

There was no overall survival benefit with oblimersen in the intent-to-treat population. However, among the patients with response, oblimersen was associated with improved clinical outcomes. Achievement of complete response/nodular partial response was correlated with both an extended time to progression and survival $(P<0.0001)$. 
In patients who remained sensitive to fludarabine, oblimersen was associated with a four-fold increase in the complete response/nodular partial response rate and a significant overall survival benefit $(P=0.05)$. A follow-up report has confirmed continued survival benefit with oblimersen for patients who achieved at least a partial response and for patients with fludarabine-sensitive disease. ${ }^{48}$ Time to progression was reported in the first report of this study ${ }^{47}$ and at 24 months, time to progression was not different, but in patients achieving a complete response or a nodular partial response, time to progression was $\geq 2$ years in $70 \%$ of patients in the oblimersen group and in $50 \%$ of those in the chemotherapy alone group.

\section{Clinical experience with oblimersen sodium in diseases other than CLL}

While this review focuses on the use of oblimersen sodium in CLL, a few additional clinical experiences are worthy of discussion. Pro et al conducted a multicenter Phase II study of oblimersen sodium in combination with rituximab in patients with recurrent B cell non-Hodgkin's lymphoma. ${ }^{49}$ Among 42 evaluable patients, the objective response rate was $42 \%$ (complete response $23 \%$ and partial response 19\%) and among patients with follicular lymphoma, the objective response rate was $60 \%$ with low-grade toxicities. The median duration of response was 12 months. A Phase III study in relapsed/refractory multiple myeloma tested the question whether addition of oblimersen sodium to dexamethasone improved time to progression or response rate. ${ }^{50}$ There were no significant improvements in time to progression or response rate upon addition of oblimersen to dexamethasone.

In a randomized Phase III study in advanced melanoma, ${ }^{51}$ 771 patients were randomized to dacarbazine alone or dacarbazine preceded by a 5-day infusion of oblimersen sodium. Progression-free survival was better in the combination arm (median, 2.6 versus 1.6 months, $P<0.001$ ), as was the objective response rate $(13.5 \%$ versus $7.5 \% ; P=0.007)$. However, the study did not meet its primary goal of improving overall survival.

\section{Future directions}

Fludarabine, cyclophosphamide, and rituximab-based chemoimmunotherapy is currently considered standard front-line therapy for patients with CLL and an indication for treatment, provided patients are considered fit to receive such therapy. However, there is still potential for improvement in this front-line regimen because progression-free survival is in the range of $65 \%$ at 3 years. ${ }^{52}$ Moreover, the depth and quality of response as determined by minimal residual disease appear to be prognostic for response duration. ${ }^{53}$ Addition of agents like oblimersen or other Bcl-2 inhibitors with low potential for myelosuppression carries the potential of improving the depth and duration of response to front-line chemoimmunotherapy. Despite promising results, addition of oblimersen has not been incorporated into front-line regimens. The lack of overall survival benefit in the intent-to-treat population and development of small molecule inhibitors of the Bcl-2 family of proteins are all likely factors for this.

Based on its limited toxicity, oblimersen could also potentially be combined with immunomodulators (lenalidomide), monoclonal antibodies (rituximab, ofatumumab, and alemtuzumab) or agents targeting B cell receptor signaling (Bruton's tyrosine kinase or PI3K [phosphoinositide-3 kinase] inhibitors) as front-line treatments for older patients with CLL or for patients with relapsed disease.

\section{Disclosure}

The authors report no conflicts of interest in this work.

\section{References}

1. Petit PX, Susin SA, Zamzami N, Mignotte B, Kroemer G. Mitochondria and programmed cell death: back to the future. FEBS Lett. 1996;396(1):7-13.

2. Susin SA, Zamzami N, Castedo M, et al. Bcl-2 inhibits the mitochondrial release of an apoptogenic protease. J Exp Med. 1996;184(4): 1331-1341.

3. Green DR, Reed JC. Mitochondria and apoptosis. Science. 1998; 281(5381):1309-1312.

4. Zamzami N, Susin SA, Marchetti P, et al. Mitochondrial control of nuclear apoptosis. J Exp Med. 1996;183(4):1533-1544.

5. Adachi S, Cross AR, Babior BM, Gottlieb RA. Bcl-2 and the outer mitochondrial membrane in the inactivation of cytochrome $\mathrm{c}$ during Fas-mediated apoptosis. J Biol Chem. 1997;272(35):21878-21882.

6. Luo X, Budihardjo I, Zou H, Slaughter C, Wang X. Bid, a Bcl2 interacting protein, mediates cytochrome $\mathrm{c}$ release from mitochondria in response to activation of cell surface death receptors. Cell. 1998;94(4):481-490.

7. Kuwana T, Bouchier-Hayes L, Chipuk JE, et al. BH3 domains of $\mathrm{BH} 3$-only proteins differentially regulate Bax-mediated mitochondrial membrane permeabilization both directly and indirectly. Mol Cell. 2005;17(4):525-535.

8. Jurgensmeier JM, Xie Z, Deveraux Q, Ellerby L, Bredesen D, Reed JC. Bax directly induces release of cytochrome $\mathrm{c}$ from isolated mitochondria. Proc Natl Acad Sci U S A. 1998;95(9):4997-5002.

9. Gross A, Jockel J, Wei MC, Korsmeyer SJ. Enforced dimerization of BAX results in its translocation, mitochondrial dysfunction and apoptosis. EMBO J. 1998;17(14):3878-3885.

10. Wolter KG, Hsu YT, Smith CL, Nechushtan A, Xi XG, Youle RJ. Movement of Bax from the cytosol to mitochondria during apoptosis. J Cell Biol. 1997;139(5):1281-1292.

11. Hsu YT, Wolter KG, Youle RJ. Cytosol-to-membrane redistribution of Bax and Bcl-X(L) during apoptosis. Proc Natl Acad Sci U S A. 1997;94(8):3668-3672.

12. Zou H, Henzel WJ, Liu X, Lutschg A, Wang X. Apaf-1, a human protein homologous to C. elegans CED-4, participates in cytochrome c-dependent activation of caspase-3. Cell. 1997;90(3):405-413. 
13. Li P, Nijhawan D, Budihardjo I, et al. Cytochrome c and dATP-dependent formation of Apaf-1/caspase-9 complex initiates an apoptotic protease cascade. Cell. 1997;91(4):479-489.

14. Cheng EH, Wei MC, Weiler S, et al. BCL-2, BCL-X(L) sequester BH3 domain-only molecules preventing BAX- and BAK-mediated mitochondrial apoptosis. Mol Cell. 2001;8(3):705-711.

15. Letai A, Bassik MC, Walensky LD, Sorcinelli MD, Weiler S, Korsmeyer SJ. Distinct BH3 domains either sensitize or activate mitochondrial apoptosis, serving as prototype cancer therapeutics. Cancer Cell. 2002;2(3):183-192.

16. Deveraux QL, Roy N, Stennicke HR, et al. IAPs block apoptotic events induced by caspase- 8 and cytochrome c by direct inhibition of distinct caspases. EMBO J. 1998;17(8):2215-2223.

17. Du C, Fang M, Li Y, Li L, Wang X. Smac, a mitochondrial protein that promotes cytochrome c-dependent caspase activation by eliminating IAP inhibition. Cell. 2000;102(1):33-42.

18. BakhshiA, Jensen JP, Goldman P, et al. Cloning the chromosomal breakpoint of $\mathrm{t}(14 ; 18)$ human lymphomas: clustering around $\mathrm{JH}$ on chromosome 14 and near a transcriptional unit on 18. Cell. 1985;41(3):899-906.

19. Cleary ML, Smith SD, Sklar J. Cloning and structural analysis of cDNAs for bcl-2 and a hybrid bcl-2/immunoglobulin transcript resulting from the $\mathrm{t}(14 ; 18)$ translocation. Cell. 1986;47(1):19-28.

20. Tsujimoto Y, Finger LR, Yunis J, Nowell PC, Croce CM. Cloning of the chromosome breakpoint of neoplastic B cells with the $t(14 ; 18)$ chromosome translocation. Science. 1984;226(4678):1097-1099.

21. McDonnell TJ, Deane N, Platt FM, et al. Bcl-2-immunoglobulin transgenic mice demonstrate extended B cell survival and follicular lymphoproliferation. Cell. 1989;57(1):79-88.

22. Barrans SL, Carter I, Owen RG, et al. Germinal center phenotype and bcl-2 expression combined with the International Prognostic Index improves patient risk stratification in diffuse large B-cell lymphoma. Blood. 2002;99(4):1136-1143.

23. Sanchez E, Chacon I, Plaza MM, et al. Clinical outcome in diffuse large B-cell lymphoma is dependent on the relationship between different cell-cycle regulator proteins. J Clin Oncol. 1998;16(5):1931-1939.

24. Mounier N, Briere J, Gisselbrecht C, et al. Rituximab plus CHOP (R-CHOP) overcomes bcl-2 - associated resistance to chemotherapy in elderly patients with diffuse large B-cell lymphoma (DLBCL). Blood. 2003;101(11):4279-4284

25. Cho-Vega JH, Rassidakis GZ, Admirand JH, et al. MCL-1 expression in B-cell non-Hodgkin's lymphomas. Hum Pathol. 2004;35(9): 1095-1100

26. Khoury JD, Medeiros LJ, Rassidakis GZ, McDonnell TJ, Abruzzo LV, Lai R. Expression of Mcl-1 in mantle cell lymphoma is associated with high-grade morphology, a high proliferative state, and p53 overexpression. J Pathol. 2003;199(1):90-97.

27. Rust R, Harms G, Blokzij1 T, et al. High expression of Mcl-1 in ALK positive and negative anaplastic large cell lymphoma. J Clin Pathol. 2005;58(5):520-524.

28. McConkey DJ, Chandra J, Wright S, et al. Apoptosis sensitivity in chronic lymphocytic leukemia is determined by endogenous endonuclease content and relative expression of BCL-2 and BAX. J Immunol. 1996;156(7):2624-2630.

29. Pepper C, Bentley P, Hoy T. Regulation of clinical chemoresistance by Bcl-2 and Bax oncoproteins in B-cell chronic lymphocytic leukaemia. Br J Haematol. 1996;95(3):513-517.

30. Robertson LE, Plunkett W, McConnell K, Keating MJ, McDonnell TJ. Bcl-2 expression in chronic lymphocytic leukemia and its correlation with the induction of apoptosis and clinical outcome. Leukemia. 1996;10(3):456-459.

31. Hanada M, Delia D, Aiello A, Stadtmauer E, Reed JC. Bcl-2 gene hypomethylation and high-level expression in B-cell chronic lymphocytic leukemia. Blood. 1993;82(6):1820-1828.

32. Reed JC, Stein C, Subasinghe C, et al. Antisense-mediated inhibition of BCL2 protooncogene expression and leukemic cell growth and survival: comparisons of phosphodiester and phosphorothioate oligodeoxynucleotides. Cancer Res. 1990;50(20):6565-6570.
33. Campos L, Sabido O, Rouault JP, Guyotat D. Effects of BCL-2 antisense oligodeoxynucleotides on in vitro proliferation and survival of normal marrow progenitors and leukemic cells. Blood. 1994;84(2):595-600.

34. Kitada S, Miyashita T, Tanaka S, Reed JC. Investigations of antisense oligonucleotides targeted against Bcl-2 RNAs. Antisense Res Dev. 1993;3(2):157-169.

35. Cotter FE, Johnson P, Hall P, et al. Antisense oligonucleotides suppress B-cell lymphoma growth in a SCID-hu mouse model. Oncogene. 1994;9(10):3049-3055.

36. Klasa RJ, Bally MB, Ng R, Goldie JH, Gascoyne RD, Wong FM. Eradication of human non-Hodgkin's lymphoma in SCID mice by BCL-2 antisense oligonucleotides combined with low-dose cyclophosphamide. Clin Cancer Res. 2000;6(6):2492-2500.

37. Klasa RJ, Gillum AM, Klem RE, Frankel SR. Oblimersen Bcl-2 antisense: facilitating apoptosis in anticancer treatment. Antisense Nucleic Acid Drug Dev. 2002;12(3):193-213.

38. Oltersdorf T, Elmore SW, Shoemaker AR, et al. An inhibitor of Bcl-2 family proteins induces regression of solid tumours. Nature. 2005;435(7042):677-681.

39. Smith MR, Jin F, Joshi I. Enhanced efficacy of therapy with antisense BCL-2 oligonucleotides plus anti-CD20 monoclonal antibody in SCID mouse/human lymphoma xenografts. Mol Cancer Ther. 2004;3(12):1693-1699.

40. Tolcher AW, Kuhn J, Schwartz G, et al. A phase I pharmacokinetic and biological correlative study of oblimersen sodium (genasense, g3139), an antisense oligonucleotide to the bcl-2 mRNA, and of docetaxel in patients with hormone-refractory prostate cancer. Clin Cancer Res. 2004;10(15):5048-5057.

41. Mita MM, Ochoa L, Rowinsky EK, et al. A phase I, pharmacokinetic and biologic correlative study of oblimersen sodium (Genasense, G3139) and irinotecan in patients with metastatic colorectal cancer. Ann Oncol. 2006;17(2):313-321.

42. Galatin PS, Advani RH, Fisher GA, et al. Phase I trial of oblimersen (Genasense(R)) and gemcitabine in refractory and advanced malignancies. Invest New Drugs. 2011;29(5):971-977.

43. Marcucci G, Byrd JC, Dai G, et al. Phase 1 and pharmacodynamic studies of G3139, a Bcl-2 antisense oligonucleotide, in combination with chemotherapy in refractory or relapsed acute leukemia. Blood. 2003;101(2):425-432.

44. Marcucci G, Stock W, Dai G, et al. Phase I study of oblimersen sodium, an antisense to $\mathrm{Bcl}-2$, in untreated older patients with acute myeloid leukemia: pharmacokinetics, pharmacodynamics, and clinical activity. J Clin Oncol. 2005;23(15):3404-3411.

45. Tolcher AW, Chi K, Kuhn J, et al. A phase II, pharmacokinetic, and biological correlative study of oblimersen sodium and docetaxel in patients with hormone-refractory prostate cancer. Clin Cancer Res. 2005;11(10):3854-3861.

46. O’Brien SM, Cunningham CC, Golenkov AK, Turkina AG, Novick SC, Rai KR. Phase I to II multicenter study of oblimersen sodium, a Bcl-2 antisense oligonucleotide, in patients with advanced chronic lymphocytic leukemia. J Clin Oncol. 2005;23(30):7697-7702.

47. O'Brien S, Moore JO, Boyd TE, et al. Randomized phase III trial of fludarabine plus cyclophosphamide with or without oblimersen sodium (Bcl-2 antisense) in patients with relapsed or refractory chronic lymphocytic leukemia. J Clin Oncol. 2007;25(9):1114-1120.

48. O'Brien S, Moore JO, Boyd TE, et al. 5-year survival in patients with relapsed or refractory chronic lymphocytic leukemia in a randomized, phase III trial of fludarabine plus cyclophosphamide with or without oblimersen. J Clin Oncol. 2009;27(31):5208-5212.

49. Pro B, Leber B, Smith M, et al. Phase II multicenter study of oblimersen sodium, a Bcl-2 antisense oligonucleotide, in combination with rituximab in patients with recurrent B-cell non-Hodgkin lymphoma. Br J Haematol. 2008;143(3):355-360.

50. Chanan-Khan AA, Niesvizky R, Hohl RJ, et al. Phase III randomised study of dexamethasone with or without oblimersen sodium for patients with advanced multiple myeloma. Leuk Lymphoma. 2009;50(4):559-565. 
51. Bedikian AY, Millward M, Pehamberger H, et al. Bcl-2 antisense (oblimersen sodium) plus dacarbazine in patients with advanced melanoma: the Oblimersen Melanoma Study Group. J Clin Oncol. 2006;24(29):4738-4745.

52. Hallek M, Fischer K, Fingerle-Rowson G, et al. Addition of rituximab to fludarabine and cyclophosphamide in patients with chronic lymphocytic leukaemia: a randomised, open-label, phase 3 trial. Lancet. 2010;376(9747):1164-1174.
53. Bottcher S, Ritgen M, Fischer K, et al. Minimal residual disease quantification is an independent predictor of progression-free and overall survival in chronic lymphocytic leukemia: a multivariate analysis from the randomized GCLLSG CLL8 Trial. J Clin Oncol. 2012;30(9):980-988.

\section{Publish your work in this journal}

Blood and Lymphatic Cancer: Targets and Therapy is an international, peer-reviewed, open access journal focusing on blood and lymphatic cancer research, identification of therapeutic targets and the optimal use of preventative and integrated treatment interventions to achieve improved outcomes, enhanced survival and quality of life for the cancer patient. The manuscript management system is completely online and includes a very quick and fair peer-review system. Visit http://www.dovepress.com/testimonials.php to read real quotes from published authors.

Submit your manuscript here: http://www.dovepress.com/blood-and-lymphatic-cancer-targets-and-therapy-journal 